\title{
Explication functions in the conditions of professionalization of thinking
}

\author{
M. M. Kashapov ${ }^{1}$
}

${ }^{1}$ P. G. Demidov Yaroslavl State University, 14 Sovetskaya str., Yaroslavl 150003, Russian Federation

DOI: $10.18255 / 1996-5648-2021-1-100-109$

Research article Full text in Russian

The article substantiates that the explication method in conditions of professionalization of the subject's thinking performs various functions. Explication allows for: firstly, the translation of unclear and uncertain intuitive representations (explicands) to the form of strictin categorical, semantic and logical form concepts (explicans); secondly, the conceptualization of a certain area of professional knowledge, bringing it into a coherent, effective system; thirdly, the detection and accounting of implicit dependencies between various knowable and transformable phenomena; fourthly, the implementation of supra-situational thinking that ensures the acquisition of valuable personal and professional neoformations by the subject. Explication (expression, distribution) of the selected professional thinking featuresof the subject as anbeingexplicatedphenomenonis carried out by differentiating the knowable phenomena: spiritual as a manifestation of the power and content of inner life; social as a refraction of social requirements in professional activity; environmental as the integration and understanding of those environmental conditions that become the means of operational coping with the difficulties encountered; resource as the implementation and multiplication of resources, primarily internal as the basis for professional and personal self-development of the subject.

Keywords: explication; professionalization; thinking; activity; resource-based thinking; subject; professional and personal development

\section{INFORMATION ABOUT AUTHORS}

\author{
Kashapov Mergalyas M. E-mail: smk007@bk.ru \\ Doc. Sc. (Psychology), Professor
}

Funding: RFBR, project No 19-013-00102a 


\title{
Функции экспликации в условиях профессионализации мышления
}

\author{
M. M. Кашапов ${ }^{1}$
}

${ }_{1}^{1}$ Ярославский государственный университет им. П. Г. Демидова, ул. Советская, 14, Ярославль, 150003, Российская Федерация

DOI: $10.18255 / 1996-5648-2021-1-100-109$

УдК 159.9.072

Научная статья

Полный текст на русском языке

В статье обосновано, что метод экспликации в условиях профессионализации мышления субъекта выполняет различные фрункции. Экспликация позволяет осуществить: во-первых, перевод неясных и неопределённых интуитивных представлений (экспликандов) к виду строгих в категориальном, семантическом и логическом виде понятий (экспликансов); во-вторых, концептуализацию определенной области профессионального познания, приведение её в целостную, действенную систему; в-третъих, обнаружение и учёт имплицитных (или неявных) зависимостей между различными познаваемыми и преобразуемыми явлениями; в-четвертых, реализацию надситуативного мышления, обеспечивающего приобретение субъектом ценных личностных и профессиональных новообразований. Экспликация (выражение, распространение) выделенных признаков профрессионального мышления субъекта как эксплицируемого явления осуществляется посредством дифференцирования познаваемых явлений: Әуховнъх как проявление силы и содержательности внутренней жизни; соииалъных как преломление в профессиональной деятельности общественных требований; средовых как интеграция и осмысление тех условий среды, которые становятся средствами оперативного совладания с возникшими трудностями; ресурснъx как реализация и преумножение ресурсов, прежде всего внутренних как основы профессионального и личностного саморазвития субъекта.

ключевые слова: экспликация; профессионализация; мышление; деятельность; ресурсность мышления; субъект; профрессиональное и личностное развитие

\section{ИНФОРМАЦИЯ ОБ АВТОРАХ}

Кашапов Мергаляс $\mid$ E-mail: smk007@bk.ru

Мергалимович. Доктор психологических наук, профессор

Финансирование: РФФИ, проект № 19-013-00102a 
Кашапов М. М.

В современной психологии особое значение приобретает экспликация полученных теоретических и эмпирических результатов. Востребованность разработки проблемы психологических понятий в контексте их включения в более широкий спектр взаимодействия человека с миром трудно переоценить. Так, Д. А. Леонтьев, анализируя понятие «саморегуляция», утверждает, что в данном понятии заложен мощный категориальный, даже парадигматический потенциал, и экспликация этого потенциала понятия саморегуляции, понимаемого как общий объяснительный принцип, позволяет прийти к далеко идущим выводам, важным для психологической науки в целом [1].

Экспликация - (от лат. explicatio - разъяснение, объяснение) уточнение понятий и утверждений естественного и научного языка с помощью средств символической логики. Экспликация применяется и как метод психологического обеспечения деятельности, и как технология развития ментальных ресурсов человека (Л. Г. Дикая, А. Л. Ж Журавлев, Т. Л. Крюкова, Г. В. Ожиганова, М. А. Холодная, С. А. Хазова, В. А. Толочек). Она используется в качестве одного из способов экспресс-мониторинга, в котором одновременно развертывается содержание обучения и профессиональной деятельности. При помощи вопросов и уточнений, комментариев, подсказок, а также совместных действий тьютора (или наставника, или эксперта) и обучаемого происходят изменения в деятельности, в развитии личности и оперативно корректируется процесс обучения (самообучения, взаимообучения, профпереподготовки, повышения квалификации). Так, В. П. Песковым проведено исследование роли стиля мышления ученого в процессе экспликации представления как психического явления. Показано, что какой-то один из способов представления информации и ее анализа в нашем сознании не является одновременно необходимым и достаточным [2]. Семиотическая интерпретация понятия границы предпринимается Лотманом в связи с экспликацией структуры и механизмов трансформации культурного пространства - семиосферы [3, с. 243].

Эксплика́ция является методом развёртывания (раскрытия) сущности того или иного познаваемого предмета (явления) посредством установления некоторого многообразия его связей и отношений с другими предметами и явлениями. Если экспликация подразумевает уточнение неопределённого понятия, имеющего место в повседневном или научном употреблении, то такое понятие называют «экспликандум», а результат экспликации - «экспликатом».

В исследовании А. Н. Алехина и А. А. Грековой установлены новые феномены мышления, сделаны подробные клинико-психологические и феноменологические описания выявленных феноменов; описаны психосемиотические механизмы работы мышления со знаками и значениями понятий. Показано, что феномены представляют собой новые формы мыш- 
ления и проявляются у успешных в обучении, социально адаптированных практически здоровых студентов вузов разных направлений обучения $[4-5]$.

Экспликация системы профессионального мышления в современных условиях образовательной среды представлена в цикле работ, выполненных под руководством И. В. Серафимович, хотя понятие «экспликация» в этих исследованиях не используется. Данной группой исследователей внесен существенный вклад в агрегацию (объединение разрозненных сведений в одну систему, в одно целое, простое сочетание установленных признаков исследуемого понятия) пока ещё слабо разработанного понятия «профессионализация мышления субъекта». Так, развитие профессионального мышления рассматривается в контексте фрормирования электронной информационно-образовательной среды вуза [6]. Обоснованы результаты, характеризующие профессионализацию мышления педагога и развитие профрессиональных компетенций в условиях конкурсов профрессионального мастерства [7]. Показано, каким образом конкурсы профессионального мастерства могут рассматриваться как фрорма развития профессиональных компетенций и профессионализации мышления педагогов [8]. Проведено исследование соотношения профессионального мышления педагогов и личностных результатов обучающихся [9]. Представляется перспективным понимание профессионализации мышления субъекта как условия личностного и профессионального развития (на примере медицинских работников) [10]. Обоснован практический выход результатов исследования профессионализации мышления и психолого-педагогической подготовки педагогов в организацию работы с личностными результатами обучающихся средствами воркшопа [11]. Внесен вклад в расширение научных представлений об акмеологических и когнитивных ресурсах, реализуемых в условиях профессионализации студентов [12]. Рассмотрены условия адаптации в профессиональной педагогической деятельности и возможности реализации когнитивных ресурсов [13]. Выделены и описаны метакогнитивные признаки профессионального мышления и особенности саморегуляции педагогов как характеристики психологического здоровья [14]. Установлены и проанализированы взаимосвязи профрессионального педагогического мышления с рефлексивностью и эмоциональным интеллектом у педагогов различного профиля [15].

Следует отметить, что метод экспликации можно применять с целью объяснения внутреннего содержания ранее неизвестных понятий, таких как «ресурсное мышление». Раскрытие психологического содержания нового понятия осуществляется посредством его сопоставления с другими качествами профессионального мышления (событийность, надситуативность, абнотивность), а также с уже известными свойствами, характеристиками надситуативности мышления, такими как прогностичность, ме- 
Кашапов М. М.

такогнитивность [16-18]. В этом контексте экспликация использовалась как метод углубленного психологического проникновения в эксплицируемые понятия [19]. Понимание профессионализации мышления нередко осуществляется опосредованно. Так, Ю. С. Филатовой проведен психологический анализ выбора стратегии конфликтного поведения как фрактора формирования клинического мышления на ранних этапах профессионализации [20]. Использование автором ситуационного анализа реализовывалось в качестве средства профессионализации клинического мышления студентов [21]. А. С. Кашаповым исследованы особенности профессионализации мышления в контексте установления критериев, стадий и уровней профрессионального развития психолога-практика [22]. Автором выявлены и обоснованы когнитивные и метакогнитивные характеристики конфликтоустойчивости в процессе социально-психологической адаптации студентов. Данные характеристики рассматриваются в качестве основы социальной профессионализации субъекта [23]. Им разработан метод анализа конкретных ситуаций как средство реализации когнитивного ресурса субъекта образовательной деятельности [24]. Г. А. Виленская утверждает, что способность к произвольной динамичной регуляции когнитивных ресурсов по-разному концептуализируется различными научными школами. Так, в западной психологической традиции, по её мнению, принято говорить об исполнительных фрунциях, в число которых входят тормозной контроль, планирование, внимание, рабочая память, когнитивная гибкость, эмоциональная регуляция и др. Ряд ученых Р. Баркли, А. Мияке, Н. Фридман, М. Баних - рассматривают их как совокупность отдельных равноправных процессов; другие - авторы модели когнитивного контроля Э. Миллер и Дж. Коэн, а также А. Арон, Т. Шаллис, П. Берджесс - убеждены, что исполнительные функции составляют единый конструкт (когнитивный контроль) с ведущей ролью фрункции внимания [25].

Принципиально новое явление не может быть понято только посредством известных субъекту законов и обобщений. При этом возникает иллюзия противоречия нового здравому смыслу, сорормированному прошлым опытом. Все переломные этапы познания неизбежно связаны с «шоком новизны». Ресурс, утверждает В. А. Толочек, характеризуется множеством актуальных и потенциальных качеств (свойств, состояний, процессов) субъекта и взаимодействующих с ним субъектов, условий среды. В рамках ресурсного подхода им постулируется признание актуализации разных условий внешней и внутренней среды субъекта на разных возрастных этапах, в разных социальных пространствах. Им сорормулирована проблема динамики актуализации ресурсов субъектом на протяжении профессиональной карьеры. Такое видение сразу же заостряет ряд сопряженных вопросов (отличия френомена «ресурс» от других психиче- 
ских феноменов; равноценности различных видов ресурсов для разных людей; связи меры актуализации человеком ресурсов разных видов и его социальной успешности; оценки параметров или меры актуализации ресурсов и др.) [26]. Автором обосновано, что поиск способов управления процессами групповой самоорганизации субъектов труда, усиление позитивных эффектов, порождаемых взаимодействиями людей, и купирование (ослабление, коррекция) негативных эффректов могут способствовать освоению новых ресурсов роста производительности индивидуального и коллективного труда [27, с. 195]. В. А. Толочек подчеркивает, что изучение проявлений "умственной работоспособности" также выявляет ограниченность некоторых методологических подходов (деятельностного и экологического подхода в частности). "Умственная работоспособностъ» не есть лишь функция субъекта деятельности, проявляющего ту или иную активность в достижении своих целей; она не есть лишь функция согласований разных воздействий в системе «человек - среда (окружение)». Есть основания рассматривать «умственную работоспособностъ» как сложный феномен в его предельно широком контексте в системе отношений «человек-мир» (курсив. - Т. В.) [28, с. 40].

Посредством применения метода экспликации нами [29-35] проведена исходная селекция множества признаков и параметров профессионализации мышления, в т. ч. и ресурсности мышления (PM), посредством которых осуществляется:

а) перенос свойств от эксплицируемого явления к эксплицирующим. Прежде всего, следует выделить дихотомические признаки PM: оперативность - отсроченность, оригинальность - традиционность; спонтанность планируемость; импульсивность - рефлексивность. Субъект, познавая и преобразовывая сложную ситуацию, стремится найти в ней реперные точки, которые потенциально могут стать внутренней духовной опорой его личностно-профессионального развития. Такой конструктивный подход позволяет творческим образом заведомое поражение обернуть в реальную победу, поскольку профессионал, благодаря надситуативному подходу, поднимается над частоколом астенических эмоций и находит осмысленные способы совладания с возникшими затруднениями;

б) поиск и отбор характеристик - носителей выделенных признаков PМ как основы личностно-профессионального развития. Такой подход позволяет мобилизоваться на основном направлении саморазвития. Для этого субъекту требуется работать на опережение и сегодня готовиться к творческому разрешению проблем завтрашнего дня;

в) экспликация (выражение, распространение) выделенных признаков PM как эксплицируемого явления через отобранные предметы (явления): духовные как проявление силы и содержательности внутренней жизни; социальные как преломление общественных требований; 
Кашапов М. М.

средовые как выражение условий среды, которые становятся средствами оперативного совладания с текущими и перспективными трудностями; ресурсные как реализация и преумножение ресурсов, прежде всего внутренних, как основы профессионального и личностного саморазвития субъекта;

г) экспликация полученных результатов позволяет сделать «вытяжку», выводы на основе рефлексии собственных действий, что способствует творческому переосмыслению выполняемой профессиональной деятельности;

д) системная экспликация объективных и субъективных детерминант, обеспечивающих эффективность деятельности и жизнедеятельности в целом.

Метод экспликации в контексте научной методологии выполняет различные функции. Экспликация позволяет осуществить: во-первых, перевод неясных и неопределённых интуитивных представлений (экспликандов) к виду строгих в категориальном и логическом виде понятий (экспликансов); во-вторых, концептуализацию той или иной области знания, приведение её в целостную систему; в-третьих, обнаружение ранее неочевидных (или неявных) зависимостей между различными познаваемыми и преобразуемыми предметами или явлениями; в-четвертых, при реализации надситуативного мышления субъект осуществляет экспликацию ментальных ресурсов и приобретает ценные личностные и профрессиональные новообразования [36].

Таким образом, представляется перспективным при определении типов экспликации реализовывать фрункцию определенного основания, позволяющую выделить общую и частную экспликации. Способность к экспликации можно целенаправленно совершенствовать как в специально смоделированных дидактических ситуациях [37], так и в тренинговых фрормах обучения творческому разрешению конфликтов [38-40].

\section{Ссылки}

1. Леонтьев Д. А. Саморегуляция как предмет изучения и как объяснительный принцип // Психология саморегуляции в XXI веке / отв. ред. В. И. Моросанова. СПб.; М.: Нестор-История, 2011 С. 74-89.

2. Песков В. П. Роль аналитического и холистического стилей мышления для экспликации представления // Вестник Московского педагогического университета. Серия Педагогика и психология. 2014. № 1 (27). С. 74-80.

3. Демин И. В. Понятие границы в семиотике культуры Ю. М. Лотмана // Ярославский педагогический вестник. 2018. № 3. С. 243-249.

4. Алехин А. Н., Грекова А. А. Особенности фрормирования мышления в условиях цифровой среды // Клиническая и специальная психология. 2019. Т. 8, № 1. С. 162-176. 
5. Алехин А.Н., Грекова А. А. «Псевдопсихопатологические» формы мышления в современных условиях // Вестник психотерапии. 2018. № 66 (71). С. 137-151.

6. Серафримович И. В., Конькова О. М., Райхлина А. В. Формирование электронной информационно-образовательной среды вуза: интеракция, развитие профессионального мышления, управление // Открытое образование. 2019. Т. 23, № 1. C. $14-26$.

7. Серафримович И. В., Харавинина Л. Н. Конкурсы профессионального мастерства как форма развития профессиональных компетенций и профессионализации мышления педагогов // Хуманитарни Балкански изследвания. 2019. Т. 3, № 2 (4). С. 75-78.

8. Серафимович И. В., Харавинина Л. Н. Профессионализация мышления педагога и развитие профессиональных компетенций в условиях конкурсов профессионального мастерства // Азимут научных исследований: педагогика и психология. 2019. Т. 8, № 2 (27) С. 382-387.

9. Профрессиональное мышление педагогов и личностных результатов обучающихся / И. В. Серафимович [и др.] // Актуальные проблемы психологии и педагогики в современном образовании: материалы III междунар. Науч.-практ. конфр. под науч. ред. Е. В. Карповой. Ярославль, 2019. С. 172-173.

10. Серафимович И. В. Профессионализация мышления субъекта как условие личностного и профессионального развития (на примере медицинских работников) // Наука - образование - профессия: системный личностно-развивающий подход: сб. / под общ. ред. Л. М. Митиной. М., 2019. С. 516-518.

11. Серафимович И. В., Беляева О. А. Профрессионализация мышления и психолого-педагогическая подготовка педагогов к работе с личностными результатами обучающихся средствами воркшопа // Вестник Костромского государственного университета. Серия: Педагогика. Психология. Социокинетика. 2019. № 2. С. 114-117.

12. Серафимович И. В. Акмеологические и когнитивные ресурсы в профессионализации студентов // Мир науки. Педагогика и психология. 2019. № 5. C. 64 .

13. Серафимович И. В., Егорова К. А. Адаптация в профессиональной педагогической деятельности и когнитивные ресурсы // Ярославский психологический вестник. 2019. № 2 (44). С. 100-102.

14. Серафимович И. В., Сабаканова А. С. Метакогнитивные признаки профессионального мышления и особенности саморегуляции педагогов как характеристики психологического здоровья // Экопсихологические исследования-6: экология детства и психология устойчивого развития: сб. науч. ст. Курск, 2020. С. 258-262.

15. Серафимович И. В., Егорова К. А. Взаимосвязь профессионального педагогического мышления с рефлексивностью и эмоциональным интеллектом у педагогов различного профиля // Методология современной психологии. 2020. № 11. С. $327-339$. 
Кашапов М. М.

16. Кашапов M. M. Когнитивное и метакогнитивное понимание структурнодинамических характеристик творческого профрессионального мышления // Творческая деятельность профессионала в контексте когнитивного и метакогнитивного подходов / под ред. М. М. Кашапова, Ю. В. Пошехоновой. Ярославль, 2012. С. 35-121.

17. Метакогнитивные основы конфликтной компетентности / под науч. ред. проф. М. М. Кашапова. Ярославль, 2012. 428 с.

18. Kashapov M. M., Serafimovich I. V., Poshekhonova Y. V. Components of metacognition and metacognitive properties of forecasting as determinants of suprasituational pedagogical thinking. // Psychologyin Russia: State of the Art . 2017. № 10 (1). P. 80-94.

9. Филатова Ю. С., Кашапов А. С. Ресурсные основы профессионализации мышления субъекта // Методология современной психологии. 2020. № 11. С. 385-404.

20. Филатова Ю. С. Выбор стратегии конфликтного поведения как фрактор формирования клинического мышления на ранних этапах профессионализации // Молодежь и будущее: профессиональная и личностная самореализация: материалы VIII Всерос. науч.-практ. конф. по психологии с междунар. участием. Владимир, 2019. С. 347-350.

21. Филатова Ю. С. Ситуационный анализ как средство профессионализации клинического мышления студентов // Актуальные проблемы совершенствования высшего образования: тезисы докл. XIV всерос. науч.-метод. Конф. Ярославль, 2020. C. $315-317$.

22. Кашапов А. С. Критерии, стадии и уровни профессионального развития психолога-практика // Ярославский психологический вестник. 2006. Вып. 19. C. $58-62$.

23. Кашапов А. С. Когнитивные и метакогнитивные характеристики конфликтоустойчивости в процессе социально-психологической адаптации студентов // Творческая деятельность профессионала в контексте когнитивного и метакогнитивного подходов / под науч. ред. проф. М. М. Кашапова, доц. Ю. В. Пошехоновой. Ярославль, 2012. С. 269-320.

24. Кашапов А.С.Методанализаконкретныхситуацийкаксредствореализации когнитивного ресурса субъекта образовательной деятельности // Актуальные проблемы совершенствования высшего образования: тезисы докл. XIV всерос. науч.-метод. конф. Ярославль, 2020. С. 130-132.

25. Виленская Г. А. Исполнительные фрункции: природа и развитие // Психологический журнал. 2016. Т. 37, № 4. С. 21-31.

26. Толочек В. А. Человек как субъект в континууме «Задатки - компетенции» // Известия Саратовского университета. Новая серия. Акмеология образования. Психология развития. 2018. Т. 7, № 1. С. 16-25.

27. Толочек В. А. «Психологические ниши»: топос и хронос в детерминации профессиональной специализации субъекта // Вестник Московского университета. Серия 14: Психология. 2019. № 1. С. 195-213. 


\section{8. Толочек В. А. Динамика умственной работоспособности.} Ч. 2: Психологические особенности 2-летних и 4-летних циклов // Психологический журнал. 2019. Т. 40, № 6. С. 31-43.

29. Кашапов М.М.Психологияпрофессиональногопедагогическогомышления: авторефр. дис. ... д-ра психол. наук. М., 2000. 48 с.

30. Кашапов M. M. Особенности сопровождения творческого мышления психолога (на довузовском, вузовском и послевузовском этапах) // Сибирский психологический журнал. Томск. 2005. № 22. С. 135-140.

31. Кашапов M. M. Акмеологические и психологические механизмы творческого мышления профессионала в контексте метакогнитивного подхода // Вестник Тверского государственного университета. Серия: Педагогика и психология. 2009. № 5. С. 4-12.

32. Кашапов M. M. Событийность мышления преподавателя как средство профессионализации и социализации студентов // Современные тенденции развития психологии труда и организационной психологии / отв. ред. Л. Г. Дикая, А. Л. Ж Журавлев, А. Н. Занковский. М.: Институт психологии РАН, 2015. С. 186-195.

33. Кашапов М. М., Филатова Ю. С., Кашапов А. С. Когнитивные компоненты творческого процесса в конфликте. Ярославль, 2018. 360 с.

34. Кашапов M. M., Кашапов А. С. Формирование профессионального творческого мышления: учебное пособие для вузов. 2-е изд., перераб. и доп. М.: Юрайт, 2020. 124 с.

35. Кашапов М. М., Пошехонова Ю. В., Кашапов А. С. Психология образовательных технологий: учебно-методическое пособие / Яросл. гос. ун-т им. П. Г. Демидова. Ярославль: ЯрГУ, 2020. 68 с.

36. Профрессионализация мышления преподавателя в контексте современных проблем педагогического образования / M. M. Кашапов [и др.] // Ярославский психологический вестник. 2019. Вып. 3 (45). С. 35-40.

37. Активные методы обучения студентов: практическое руководство / отв. за вып. И. М. Лоханина, М. М. Кашапов, Н. В. Клюева; Яросл. гос. ун-т им. П. Г. Демидова. Ярославль: ЯрГУ, 2005. 118 с.

38. Кашапов А. С. Обучение старшеклассников творческому разрешению конфрликтов // Ярославский психологический вестник. 2007. № 20. С. 151-154.

39. Кашапов М. М., Филатова Ю. С., Кашапов А. С. Событийно-когнитивные компоненты профессионализации субъекта. Ярославль, 2018. 392 с.

40. Кашапов M. M. Надситуативное мышление как когнитивный ресурс личности // Известия Иркутского государственного университета. Серия: Психология. 2017. Т. 22. С. 3-9. 